\title{
Promoting deeper learning in pharmacy education using team-based learning
}

\author{
M J Eksteen, ${ }^{1,2} \mathrm{PhD}(\mathrm{HPE}) ;$ G M Reitsma, ${ }^{2} \mathrm{PhD}$; E Fourie, ${ }^{3} \mathrm{PhD}$ \\ ${ }^{1}$ Division Health Sciences Education, Office of the Dean, Faculty of Health Sciences, University of the Free State, Bloemfontein, South Africa \\ ${ }^{2}$ Centre for Health Professional Education, Faculty of Health Sciences, North-West University, Potchefstroom, South Africa \\ ${ }^{3}$ Statistical Consultation Services, North-West University, Potchefstroom, South Africa
}

Corresponding author: M J Eksteen (mariet.eksteen@gmail.com)

\begin{abstract}
Background. The benefit of deep learning compared with surface learning is the ability to retrieve, apply and integrate previously learnt knowledge rather than simply memorising course content most likely to be evaluated during assessments. Team-based learning (TBL) is an educational strategy that echoes the purpose of deeper learning.

Objectives. To identify whether TBL as a teaching strategy increases pharmacy students' understanding of theoretical work.

Method. Fourth-year pharmacy students completed a questionnaire consisting of biographical data (gender, age and ethnicity) and 16 questions on their understanding of course content. A total of 183 students (91.5\%) participated after giving informed consent that their data may be included in the study.

Results. The results indicated that, due to the implementation of TBL in the course, students perceived that they learnt more and made more effort, experienced increased understanding of content, perceived higher knowledge retention, performed better during assessments in the module where TBL was implemented and felt that course outcomes were achieved more easily.

Conclusion. TBL as a teaching strategy could potentially promote deeper learning of course content.
\end{abstract}

Afr J Health Professions Educ 2021;13(2):105-109. https://doi.org/10.7196/AJHPE.2021.v13i2.878

Traditional lecture methods, where the lecturer teaches for the full duration of class, result in students being passive learners owing to limited student engagement. ${ }^{[1]}$ These students mostly memorise module content ${ }^{[2]}$ and accept all course content without questioning or distinguishing underlying principles or patterns. ${ }^{[3]}$ The passive nature of the lecture-centred class provides a lower level of knowledge retention and cognition for students. ${ }^{[4]}$ The lecture method encourages surface learning, as defined by Marton and Säljö, ${ }^{[5]}$ where students only remember facts they think they would be asked during assessments to receive a passing grade.

In contrast to passive learning, active learning strategies allow students to engage more actively with course content, which promotes students' learning experiences. ${ }^{[6]}$ Currently, exit-level competencies for health professionals have moved from knowing information to solving complex problems, ${ }^{[7]}$ which require collaboration and integration of information. To achieve this, students need not only understand, but have to interact critically with course content to relate ideas to previous knowledge and experiences. ${ }^{[3,5]}$ This method results in deeper learning, where holistic insight into course content and the ability to integrate information take place through use of analytical skills and cross-referencing. However, deep learning depends on the student's level of engagement with course content. ${ }^{[8]}$ It is therefore important that health professions education incorporate strategies that foster deep learning.

The purpose of team-based learning (TBL) is to deepen students' learning. ${ }^{[9]}$ This structured, student-centred, active learning strategy ${ }^{[10]}$ includes three phases to deepen students' learning of course content. Prior to class, students have to study the selected assigned reading to understand basic concepts and ideas relevant to the scheduled class. The assigned reading may include textbooks, scientific articles or lecture notes. ${ }^{[11,12]}$ At the beginning of the class, students' preparation is assessed through individual readiness assurance tests (iRAT) and team readiness assurance tests (tRAT), focusing on foundational concepts. The purpose of this phase is to assess whether students have a sound understanding of basic and fundamental concepts required for the next phase. ${ }^{[13]}$ Lastly, the remaining class time is allocated to the application of course concepts in exercises designed to deepen the students' understanding of course content. ${ }^{[10]}$ These applicationfocused team exercises foster participatory discussions to solve the problem, which promote collaboration and critical thinking. ${ }^{[14]}$

In a previous study on the effect of TBL on students' learning, Elliot ${ }^{[15]}$ found that students in TBL showed a greater engagement and involvement in their learning compared with their involvement in the traditional lecture. She also acknowledged that students gained knowledge from their peers, similar to the working environment, where it will be expected of them to work and collaborate with each other to solve patient problems. In another study, faculty members from several US colleges and schools of pharmacy revealed that they perceive TBL as an educational strategy that not only fosters student learning and engagement in course content, but also supports the achievement of educational outcomes. ${ }^{[11]}$ Huitt et al. ${ }^{[16]}$ reported on the academic benefits of TBL on students' performance, as it led to improved application of content and an increase in their problem-solving abilities.

Although several studies included questions to determine students' understanding of course content when TBL was implemented, no study was found that included a comprehensive investigation into whether students' achievement of learning outcomes had improved, as well as their understanding of course content and knowledge retention, compared with 
traditional lecture methods. In this study, we investigated whether TBL as a teaching strategy increased pharmacy students' understanding of theoretical work (curriculum), thus promoting deeper learning.

\section{Method}

\section{Target and sample population}

The target population consisted of all fourth-year pharmacy students $(N=200)$ enrolled in a pharmacy practice course, where TBL was introduced for the first time. Although all students in the target population were invited to participate in this research, not all students agreed to participate. The final sample size consisted of 183 (91.5\%) students.

Pearson's $\chi^{2}$ test was used to determine if the sample represented the target in terms of age, gender and ethnic group. The $p$-values $>0.05(0.67$, 0.91 and 0.79 , respectively) indicate no statistically significant association. Therefore, the sample population represented the target population in terms of biographical data (Table 1).

\section{Research instrument}

A questionnaire was developed based on existing information acquired through an intensive literature study on TBL in undergraduate health professions education. The questionnaire consisted of biographical data, such as age, gender and ethnic group, as well as 16 questions related to students' understanding of theoretical work. Students had to indicate their level of agreement with the statements on a Likert scale of $1-4$, where 1 indicated 'strongly disagree' and 4 'strongly agree'.

As the questionnaire was developed for this purpose, it was piloted through an exploratory investigation to assure validity before utilisation in the main investigation. ${ }^{[17]}$ Cognitive interviews with students who were not part of the study population were conducted one-on-one between the student and the researcher. The main difference between conducting a cognitive interview and other forms of interviews is that the former is used to gather information about the functioning of the research instrument rather than the collection of data. Secondly, cognitive interviews are more flexible and rely heavily on probe questions rather than verbatim administration of a standardised instrument. ${ }^{[18]}$ The purpose was to determine whether these students: (i) could understand the questions; (ii) were familiar with the terminology used in the questions; (iii) could answer the questions; and (iv) had any advice or suggestions on restructuring or rephrasing of the questions, as suggested by Wills. ${ }^{[18]}$ Content validity was ensured through the use of experts in health

Table 1. Biographical data of target and sample population in terms of gender, age and ethnic groups

\begin{tabular}{lll}
\hline Biographical data & $\begin{array}{l}\text { Target population } \\
(\boldsymbol{N = 2 0 0}), \boldsymbol{n}(\mathbf{\%})\end{array}$ & $\begin{array}{l}\text { Sample population } \\
(\boldsymbol{n}=\mathbf{1 8 3}), \boldsymbol{n}(\mathbf{\%})\end{array}$ \\
\hline $\begin{array}{l}\text { Gender } \\
\quad \text { Male }\end{array}$ & $41(20.5)$ & $34(18.6)$ \\
$\quad$ Female & $159(79.5)$ & $147(80.3)$ \\
$\begin{array}{l}\text { Age (on 31 December 2016), } \\
\text { years }\end{array}$ & \\
$\leq 22$ & $130(65.0)$ & $117(63.9)$ \\
$>22$ & $70(35.0)$ & $65(35.3)$ \\
Ethnic group & $183(91.5)$ & $166(90.7)$ \\
$\quad$ White & $17(8.5)$ & $17(8.3)$ \\
Other &
\end{tabular}

professions education and pharmacy, who reviewed the questionnaire and gave their opinions on some aspects: (i) clarity of the questions; (ii) time needed to complete the questionnaire; (iii) presence of bias in questions; and (iv) suggestions and/or recommendations. Finally, the questionnaire was reviewed by a statistician for face validity. The recommendations were included to improve the quality of the questionnaire.

\section{Ethical approval and data collection}

All students in the target population were invited to participate in the study and received a leaflet containing information regarding its purpose, researchers, procedures, benefits, risks/discomforts, cost/remuneration, access to data, inquiries, funding, ethical approval and feedback on the findings. Participation was voluntary and students were under no obligation to participate. Those who were willing to participate completed an informed consent form. It was explained to students that, should they decide to withdraw from the study at any point, even if they did agree to participate initially, it would not affect them or their course marks in any way. All data were collected anonymously; therefore, it was not possible to trace the questionnaire back to the student. Ethical approval was granted by the Ethics Committee of the Faculty of Health Sciences at the University of the Free State (ref. no. ECUFS 107/2015) and the Health Research Ethics Committee of the Faculty of Health Sciences at North-West University (ref. no. NWU-0018215-S1) prior to commencement of the study.

Data were collected during a scheduled class in the particular course. Questionnaires were completed and collected separately from the informed consent forms to adhere to anonymity. The quantitative data were analysed using SPSS version 23 (IBM Corp., USA) to determine descriptive statistics, such as percentage, mean and standard deviation (SD), exploratory factor analysis (EFA), Cronbach's $\alpha$, Spearman's rho correlation coefficients, as well as independent sample $t$-tests with Cohen's $d$-value.

\section{Results}

The results of the questionnaire are presented in Table 2. For each of the 16 questions, the percentages for each response option are indicated, as well as the mean and SD.

An EFA indicated that the first 5 questions could be grouped together to form a factor regarding how students learnt through their own understanding. The factor loadings of the questions ranged between 0.375 and 0.942 . Cronbach's $\alpha$ of 0.800 confirmed internal reliability. The 3 questions set out below formed a factor describing how students learnt from others. Factor loadings ranged between 0.316 and 0.690. Although Cronbach's $\alpha$ was lower than the guideline value of $0.7(\alpha=0.529), \geq 0.5$ is also sufficient for the early stages of research; ${ }^{[19]}$ however, interpretation should be done with caution. The third factor included the last 8 questions on learning through TBL and/or teams and had factor loadings between 0.275 and 0.569 . Cronbach's $a$ of 0.761 indicated internal reliability for this factor. Questions indicated with an asterisk were formulated in a negative trend.

\section{Learning through own understanding}

The results indicated that students' understanding of module content increased with the practical application thereof in a team $\left(\mathrm{Q} 1^{*}\right.$, mean 1.79 (SD 0.684)) and through teaching their team members (Q2, $3.12(0.640))$. Students indicated that problem-solving in a team was an effective way to practise what was learnt (Q3, $3.32(0.653))$. The majority of students claimed to perform better in assessments where TBL was used than with traditional 
Table 2. Results of the team-based learning questionnaire

\begin{tabular}{|c|c|c|c|c|c|c|}
\hline \multirow[b]{2}{*}{$\begin{array}{l}\text { Quote } \\
\text { reference }\end{array}$} & \multirow[b]{2}{*}{ Student reference } & \multicolumn{4}{|c|}{ Percentage } & \multirow[b]{2}{*}{ Mean (SD) } \\
\hline & & $\begin{array}{l}\text { Strongly } \\
\text { disagree, } \\
1\end{array}$ & $\begin{array}{l}\text { Disagree, } \\
2\end{array}$ & $\begin{array}{l}\text { Agree, } \\
3\end{array}$ & $\begin{array}{l}\text { Strongly } \\
\text { agree, } \\
4\end{array}$ & \\
\hline \multicolumn{7}{|c|}{ Learning through own understanding } \\
\hline $1^{*}$ & $\begin{array}{l}\text { My understanding of the course content did not increase } \\
\text { with the practical application of it in a team }\end{array}$ & 33.3 & 56.8 & 6.60 & 2.70 & $1.79(0.684)$ \\
\hline 2 & $\begin{array}{l}\text { Teaching my team members confirmed my own } \\
\text { understanding of difficult concepts }\end{array}$ & 2.2 & 8.2 & 63.4 & 24.6 & $3.12(0.640)$ \\
\hline 3 & $\begin{array}{l}\text { Solving problems in a team is an effective way to practise } \\
\text { what I have learnt }\end{array}$ & 2.2 & 3.8 & 54.1 & 39.9 & $3.32(0.653)$ \\
\hline 4 & $\begin{array}{l}\text { I performed better in assessments where team-based } \\
\text { learning was used to cover the material than on assessments } \\
\text { where only traditional lectures were used }\end{array}$ & 4.4 & 15.8 & 48.1 & 31.7 & $3.07(0.805)$ \\
\hline 5 & $\begin{array}{l}\text { We used feedback regarding team performances to help the } \\
\text { team to improve the effectiveness }\end{array}$ & 4.4 & 22.4 & 57.4 & 15.8 & $2.85(0.733)$ \\
\hline \multicolumn{7}{|c|}{ Learning from others } \\
\hline $6^{*}$ & $\begin{array}{l}\text { Learning from mistakes while working in a team did not } \\
\text { help me to remember information better }\end{array}$ & 35.5 & 48.6 & 11.5 & 4.4 & $1.85(0.790)$ \\
\hline $7^{*}$ & $\begin{array}{l}\text { I did not learn any new knowledge from fellow team } \\
\text { members }\end{array}$ & 54.1 & 36.1 & 4.9 & 4.4 & $1.59(0.779)$ \\
\hline $8^{*}$ & $\begin{array}{l}\text { Assessments for this course were not in line with the } \\
\text { learning outcomes }\end{array}$ & 59.6 & 36.1 & 3.8 & 0 & $1.44(0.570)$ \\
\hline \multicolumn{7}{|c|}{ Learning through team-based learning and/or teams } \\
\hline $9^{*}$ & $\begin{array}{l}\text { Team-based learning did not promote my achievement of } \\
\text { the learning outcomes }\end{array}$ & 42.1 & 50.8 & 4.9 & 2.2 & $1.67(0.673)$ \\
\hline 10 & $\begin{array}{l}\text { Learning outcomes set in this module were achieved easier } \\
\text { due to the team-based learning approach }\end{array}$ & 1.1 & 4.9 & 55.7 & 38.3 & $3.31(0.671)$ \\
\hline 11 & $\begin{array}{l}\text { Teams helped me learn course content better compared } \\
\text { with studying alone }\end{array}$ & 4.9 & 11.5 & 49.7 & 33.3 & $3.12(0.798)$ \\
\hline 12 & $\begin{array}{l}\text { Teamwork helped me to learn more than I would have } \\
\text { learnt on my own }\end{array}$ & 4.9 & 15.3 & 47.5 & 32.2 & $3.07(0.819)$ \\
\hline 13 & $\begin{array}{l}\text { Team participation helped me to understand course content } \\
\text { better than I would have understood it on my own }\end{array}$ & 2.7 & 10.4 & 53.6 & 33.3 & $3.17(0.720)$ \\
\hline 14 & $\begin{array}{l}\text { Team-based learning helped me to remember the content } \\
\text { better over a long period }\end{array}$ & 2.7 & 13.1 & 52.5 & 31.7 & $3.13(0.737)$ \\
\hline 15 & $\begin{array}{l}\text { It is necessary to have a traditional lecture before a team- } \\
\text { based learning session on the same course content }\end{array}$ & 5.5 & 18.0 & 38.3 & 38.3 & $3.09(0.881)$ \\
\hline $16^{*}$ & $\begin{array}{l}\text { Team-based learning did not increase my interest in the } \\
\text { course }\end{array}$ & 20.8 & 47.5 & 24.6 & 7.1 & $2.18(0.842)$ \\
\hline
\end{tabular}

lecture methods (Q4, 3.07 (0.805)). Students used feedback regarding team performances to improve their learning and to help the team be more effective (Q5, 2.85 (0.733)).

\section{Learning from others}

Learning from mistakes helped students to remember information better $\left(\mathrm{Q6}^{*}, 1.85\right.$ (0.790)). Students also learnt new knowledge from fellow team members (Q7* 1.59 (0.779)). Assessments were in line with the learning outcomes set for the course (Q8*, $1.44(0.570))$.

\section{Learning through TBL and/or teams}

TBL promoted students' achievement of the learning outcomes of the course $\left(\mathrm{Q9}^{*}, 1.67(0.673)\right)$. Learning outcomes were achieved more easily
(Q10, $3.31(0.671))$ and content was remembered better over a long period (Q14, 3.13 (0.737)). Working in teams helped students to learn better (Q11, $3.12(0.798))$, learn more (Q12, 3.07 (0.819)) and understand course content better $(\mathrm{Q} 13,3.17(0.720))$ than they would have if they learnt on their own. However, students were convinced that a traditional lecture should be presented before a TBL session (Q15, 3.09 (0.881)). TBL did increase students' interest in the course $\left(\mathrm{Q} 16^{*}, 2.18\right.$ (0.842)).

\section{Correlation between factors and age}

Spearman's rho did not indicate practically or statistically significant correlations between age and learning through own understanding $(r=0.004$; $p=0.955)$, learning from others $(r=0.141 ; p=0.057)$ and learning though TBL and/or teams $(r=0.149 ; p=0.045)$. 


\section{Correlation between factors}

Spearman's rho indicated statistically significant correlations between learning through own understanding and learning from others $(r=-0.418$; $p=0.0001$ ), learning through own understanding and learning through TBL and/or teams ( $r=0.702 ; p=0.0001)$ and learning from others and learning through TBL and/or teams ( $r=-0.472 ; p=0.0001)$.

\section{Independent $\boldsymbol{t}$-tests between factors and gender or ethnicity}

Independent $t$-tests with Cohen's $d$-value indicated no practically or statistically significant differences between female and male students $(d<0.18)$ or between white and other ethnic groups (black African, Asian, coloured, Indian and Korean $)(d<0.08)$ for any of the factors. The Mann-Whitney test for differences between two independent groups on a continuous measure also indicated no practically or statistically significant differences between two ethnic groups for any factor $(d<0.02 ; p>0.781)$.

\section{Discussion}

The purpose of this study was to identify whether TBL as a teaching strategy in an undergraduate pharmacy curriculum increased students' understanding of the theoretical work presented during the course. The study formed part of a larger research project to develop guidelines for the implementation of TBL in undergraduate pharmacy education in South Africa (SA). As this was the first time that TBL was implemented in pharmacy education at the University of the Free State, Bloemfontein, SA, there are no other data for comparison of the findings.

\section{Learning through own understanding}

Students indicated that their understanding of course content was increased owing to its practical application. Deeper learning in TBL was achieved during the application exercise, according to their experience, where students were required to apply course concepts to solve significant problems they are most likely to face in practice. ${ }^{[9]}$ These exercises enhanced learning by forcing students to re-examine and, where needed, modify their assumptions and/or interpretations of their pre-class preparation. Students also acknowledged that teaching their team members confirmed their own understanding of difficult concepts. Students indicated that solving problems in a team was an effective way to practise what they had learnt.

In assessments where students are required to reproduce knowledge, students indicated that they performed better in tests on material learnt through TBL than by traditional lecture methods. This was an easy comparison for students to make, as they were exposed to TBL in one course and still continued with traditional lecture methods in the other four courses, all running simultaneously during the semester. This finding is in line with those in other studies, which found that students performed better in examinations when TBL was used. ${ }^{[16]}$

Students agreed that feedback regarding team performances helped the team be more effective. Immediate feedback is considered one of four essential elements in TBL. Feedback is provided to students after the tRAT and the team application exercise so that students can correct any misunderstandings immediately.

\section{Learning from others}

Students indicated that they learnt new knowledge from fellow team members - either from other students' more detailed study or from course- related life experiences. Students found that knowledge retention was also reinforced by learning from mistakes while working in a team. As mentioned above, feedback on the tRAT and the application exercise was provided directly afterwards, providing the opportunity for students to correct misunderstandings and misconceptions immediately.

Students perceived assessments to be fair, as they were in line with the learning outcomes of the course. This finding is important to acknowledge, as better grades due to TBL may be perceived by critics as easier assessments. The difference is that, instead of covering theory in class and then exposing students to application in the assessment, application exercises in TBL are part of in-class activities.

\section{Learning through $\mathrm{TBL}$ and/or teams}

Students indicated that TBL not only promoted the achievement of learning outcomes set in the course, but also made it easier to achieve those outcomes. When designing a TBL course, the first set of decisions is to identify the instructional goals and learning outcomes. These are needed to determine the assigned reading that is necessary for students to prepare sufficiently for the TBL session. ${ }^{[9]}$ Several studies concluded that the setting of learning objectives is the single most important aspect of helping students to do the assigned reading for their preparation. ${ }^{[12,16]}$

Students indicated that teams and teamwork helped them to learn more and to learn course content better that they would have learnt on their own. Due to the lively discussions used in TBL during the tRAT, as well as the application exercises, students engage with course content while answering questions. ${ }^{[7]}$ It is expected of students to actively participate in sharing opinions and even make good, logical arguments to persuade others of their viewpoint. They indicated that team participation helped them to understand module content better than if they had been studying on their own. Students experienced that teams are able to accomplish more than the sum of individual members' contributions, the greatest difference between 'groups' and 'teams. ${ }^{[20]}$

During learning, information stored in short-term memory decays very rapidly, e.g. when cramming before examinations. To be able to use information in the future, it should be transferred to long-term memory and be retrievable when needed. ${ }^{[21]}$ Students indicated that TBL helped them to remember course content better over a long period. We also found that, due to the increased awareness of the application of course content from the application exercises, it could have increased students' interest in the course.

TBL moved the lecturing of theoretical concepts out of the classroom to pre-class preparations to use scheduled class time for the application of knowledge. However, almost $80 \%$ of students felt that it is necessary to have a traditional lecture before a TBL session on the same course content. This view could be due to the feeling of uncertainty, as students have to rely on their own preparation, and indicates that they would like to clarify some uncertainties before individual tests.

There were significant correlations between the three factors, indicating that when you learn through own understanding, you will most probably be able to learn from others and through TBL and/or the team.

\section{Conclusion}

This study investigated whether fourth-year pharmacy students experienced an increased understanding of theoretical work during the course. It is clear that, according to these students, TBL helped them to learn more than they would have learnt on their own, increased their understanding of course 
concepts, enhanced their knowledge retention, improved their individual performance during assessments and enabled easier achievement of course outcomes. From these students' experiences, TBL could provide pharmacy education the opportunity to deepen students' learning by integrating and applying course content during real-life case studies. It would be interesting to investigate the effect of TBL on other pharmacy curricula in Africa. Future studies could also test retention over a longer period of time to confirm deeper learning.

Declaration. The research for this study was done in partial fulfilment of the requirements for MJE's PhD degree at the University of the Free State (awarded in 2017).

Acknowledgements. The authors gratefully acknowledge the assistance received from the participants and role-players in the overall $\mathrm{PhD}$ study.

Author contributions. MJE designed the study, wrote the protocol, collected data and performed the analysis, interpreted data and wrote the manuscript. GMR was the supervisor of the study, reviewed the protocol and manuscript and contributed substantially to the conceptualisation, design, analysis and interpretation of data and scientific content. EF performed all the statistical analyses. All authors approved the final version of the manuscript.

Funding. This research was partially funded by a grant from the Health and Welfare Sector Education Training Authority (HWSETA).

Conflicts of interest. None.

\footnotetext{
1. Clark MC, Nguyen HT, Bray C, Levine RE. Team-based learning in an undergraduate nursing course. J Nurs Educ 2008;47(3):111-117. https://doi.org/10.3928/01484834-20080301-02

2. Altintas L, Altintas O, Caglar Y. Modified use of team-based learning in an ophthalmology course for fifth-yea medical students. Adv Physiol Educ 2014;38:46-48. https://doi.org/10.1152/advan.00129.2013

3. Entwistle NJ, Ramsden P. Understanding Student Learning. London: Croom Helm, 1983.
}

4. Deslauriers L, Schelew E, Wieman C. Improved learning in a large-enrolment physics class. Science 2011:332(6031):862-864. https://doi.org/10.1126/science.1201783

5. Marton E, Säljö R. On qualitative differences in learning: Outcome as a function of learners' conception of task. Brit J Educ Psychol 1976;46:115-127. https://doi.org/10.1111/j.2044-8279.1976.tb02304.x

6. Hutchings P, Huber MT, Ciccone A. The Scholarship of Teaching and Learning Reconsidered. Institutional Integration and Impact. San Francisco: Jossey-Bass, 2011.

7. Sibley J, Parmelee DX. Knowledge is no longer enough: Enhancing professional education with team-base learning. In: Michaelson LK, Sweet M, Parmelee DX, eds. Team-based Learning: Small Group Learning's Next Big Step. San Francisco: Jossey-Bass, 2008:41-54.

8. Ramsden P. The context of learning in academic departments. In: Marton F, Hounsell D, Entwistle N, eds. The Experience of Learning. Edinburgh: Scottish Academic Press, 1997:198-216.

9. Michaelsen LK, Sweet M. Fundamental principles and practices of team-based learning. In: Michaelsen LK, Parmelee DX, McMahon KK, Levine RE, eds. Team-based Learning for Health Professions Education: A Guide to Using Small Groups for Improving Learning. Virginia: Stylus, 2008:9-34.

10. Mennenga HA, Smyer T. A model for easily incorporating team-based learning into nursing education. Inter J Nurs Mennenga HA, Smyer T. A model for easily incorporating team-
Educ Schol 2010;7(1). https://doi.org/10.2202/1548-923X.1924

11. Allen RE, Copeland J, Franks AS, et al. Team-based learning in US colleges and schools of pharmacy. Am J Pharm Educ 2013;77(6):115. https://doi.org/10.5688/ajpe776115 2013

12. Inuwa IM. Perceptions and attitudes of first-year medical students on a modified team-based learning (TBL) Inuwa IM. Perceptions and attitudes of first-year medical students on
strategy in anatomy. Sultan Qaboos University Med J 2012;12(3):336-343.

13. Michaelsen LK. Getting started with team-based learning. In: Michaelsen LK, Knight AB, Fink LD, eds. Team-based Learning: A Transformative Use of Small Groups in College Teaching. Virginia: Stylus, 2004:27-50.

14. Hawkins D. Rationale and methods for developing team-based learning education. In: Hawkings D. A Team-based Learning Guide for Faculty in the Health Professions. Bloomington, IN: AuthorHouse, 2014:1-10.

15. Elliot S. Using a modified team-based learning approach to teach nursing students about communicable diseases control and community health nursing. J Nurs Educ 2014;53(1):651-653. https://doi.org/10.3928/0148483420141027-01

16. Huitt TW, Killins A, Brooks WS. Team-based learning in the gross anatomy laboratory improves academic performance and students' attitudes towards teamwork. Anat Sci Educ 2014;8(2):95-103. https://doi.org/10.1002/ ase. 1460

17. Delport CSL, Roestenburg WJH. Quantitative data-collection methods: Questionnaires, checklists, structured observation and structured interview schedules. In: De Vos AS, Strydom H, Fouché CB, Delport CSL, eds. Research observation and structured interview schedules. In: De Vos AS, Strydom H, Fouche CB, Delport CSL, eds. Researc

18. Wills GB. Cognitive Interviewing: A Tool for Improving Questionnaire Design. Thousand Oaks: SAGE, 2005:5-6; 35-54

19. Field A. Discovering Statistics Using IBM SPSS Statistics. 4th ed. London: SAGE, 2014

20. Michaelsen LK, Sweet M. Creating effective team assignments. In: Michaelsen LK, Parmelee DX, McMahon KK, Levine RE, eds. Team-based Learning for Health Professions Education: A Guide to Using Small Groups or Improving Learning. Virginia: Stylus, 2008:35-59.

21. Bruning RH, Schraw GJ, Ronning RR. Cognitive Psychology and Instruction. 2nd ed. Englewood Cliffs, NJ: Prentice Hall, 1994.

Accepted 29 July 2020. 